Gut and Liver, Vol. 11, No. 6, November 2017, pp. 747-760

\title{
Sessile Serrated Adenomas: How to Detect, Characterize and Resect
}

\author{
Michael X. Ma ${ }^{1}$ and Michael J. Bourke ${ }^{1,2}$ \\ ${ }^{1}$ Department of Gastroenterology and Hepatology, Westmead Hospital, and ${ }^{2}$ University of Sydney, Sydney, Australia
}

Serrated polyps are important contributors to the burden of 760) colorectal cancers (CRC). These lesions were once considered to have no malignant potential, but currently up to $30 \%$ of all CRC are recognized to arise from the serrated neoplasia pathway. The primary premalignant lesions are sessile serrated adenomas/polyps (SSA/Ps), although traditional serrated adenomas are relatively uncommon. Compared to conventional adenomas, SSA/Ps are morphologically subtle with indistinct borders, may be difficult to detect endoscopically, are more prevalent than previously thought, are associated with synchronous and metachronous advanced neoplasia, and have a higher risk of incomplete resection. Although many lesions remain "dormant," progressive disease is associated with the development of dysplasia and more rapid progression to $\mathrm{CRC}$. As a result, SSA/Ps are strongly implicated in the development of interval cancers. These factors represent unique challenges that require a meticulous approach to their management. In this review, we summarize the contemporary literature on the characterization, detection and resection of SSA/Ps. (Gut Liver 2017;11:747-

Key Words: Sessile serrated adenoma; Detection; Endoscopic imaging; Histology; Endoscopic resection

\section{INTRODUCTION}

Sessile serrated adenomas/polyps (SSA/Ps), hyperplastic polyps (HPs) and traditional serrated adenomas (TSAs) form a heterogeneous group of lesions known as serrated polyps. ${ }^{1,2}$ These lesions share a common serrated or 'saw-toothed' histological appearance of their epithelial crypts, with each subtype being defined by specific architectural features, location and extent of the proliferative zone. The classification of serrated polyps has evolved over time, reflecting advances in our understanding of their histopathological, morphological and molecular features (Table 1). ${ }^{3,4}$ Before the turn of the century, virtually all serrated polyps were called HPs, as these lesions were believed to have no risk of malignancy and therefore were of little clinical significance. ${ }^{5,6}$ We now also know SSA/Ps and TSAs have the po-

Table 1. Endoscopic, Histologic, and Molecular Features of Sessile Serrated Adenoma/Polyps

\begin{tabular}{|c|c|c|c|}
\hline & Endoscopic & Histologic & Molecular \\
\hline \multirow[t]{4}{*}{ Nondysplastic } & Flat (0-IIa/0-IIb) morphology & Saw-toothed architecture of crypt epithelium & $B R A F$ V600E mutation \\
\hline & Pale colour, indistinct borders & Boot shaped crypts +/- goblet/mucinous & CIMP-high \\
\hline & Mucous cap, surrounding rim of debris/stool & cells at base & MLH1 promotor methylation \\
\hline & Type II-0 pit pattern & Pseudoinvasion & KRAS mutations (infrequent) \\
\hline \multirow[t]{4}{*}{ Dysplastic } & Transition from flat to nodular, sessile or & Adenomatous dysplasia* (most common) & Reduced expression of $M L H 1$ \\
\hline & depressed area & Serrated dysplasia $^{\dagger}$ (less common) & Microsatellite instability \\
\hline & Type III-V pit pattern & & Silencing of other tumor \\
\hline & NICE 2, Sano II on NBI & & suppressor genes $^{\ddagger}$ \\
\hline
\end{tabular}

CIMP, CpG island methylator phenotype; NICE, narrow band imaging (NBI) international colorectal endoscopic classification.

*Characterized by elongated penicillate nuclei with hyperchromasia, nuclear pseudostratification and amphophilic cytoplasm; ${ }^{\dagger} \mathrm{Characterized} \mathrm{by}$ cells with a more cuboidal shape and eosinophilic cytoplasm, enlarged vesicular nuclei and prominent nucleoli; ${ }^{3}{ }^{\ddagger}$ Including p16INK4a, IGFBP7 and MGMT.

Correspondence to: Michael J. Bourke

Department of Gastroenterology and Hepatology, Westmead Hospital, C/- Suite 106a, 151-155 Hawkesbury Road, Westmead, Sydney 2143, Australia

Tel: +61-2-9845-5555, Fax: +61-2-9845-5637, E-mail: michael@citywestgastro.com.au

Received on October 27, 2016. Accepted on December 6, 2016. Published online May 11, 2017

pISSN 1976-2283 eISSN 2005-1212 https://doi.org/10.5009/gnl16523

@ This is an Open Access article distributed under the terms of the Creative Commons Attribution Non-Commercial License (http://creativecommons.org/licenses/by-nc/4.0) which permits unrestricted non-commercial use, distribution, and reproduction in any medium, provided the original work is properly cited. 
tential for dysplasia and subsequent malignant transformation, and account for up to $30 \%$ of all colorectal cancers (CRC). ${ }^{2}$ The World Health Organization (WHO) classification, last updated in 2010, standardized terminology and definitions of serrated lesions. ${ }^{1}$ However, the detection of SSA/Ps may be hampered due to a range of factors. These polyps are usually found in the right colon where bowel preparation can be poor, have a flat morphology with indistinct borders, pale surface and may be concealed by a mucous cap or stool debris. ${ }^{2,5,7}$ As a result, SSA/ Ps may be easily missed or be inadequately resected, contributing to the development of interval cancers. ${ }^{8-10}$ Recognizing these lesions as important cancer precursors, knowledge regarding their identification and management is paramount for all endoscopists.

\section{SCALE OF THE PROBLEM: IMPORTANCE OF SESSILE SERRATED ADENOMAS}

Previous studies reported SSA/P prevalence of between $0.6 \%$ and 5.3\%, probably reflecting differences in endoscopic detection and variations in histological definitions. ${ }^{11-15}$ Recent work, however, suggests the prevalence may be higher. For example, a single center 4-year European study in a screening population of 3,364 patients with 4,251 resected and histologically confirmed polyps found 399 of these lesions were SSA/Ps. ${ }^{16}$ The prevalence of SSA/Ps overall was $8.2 \%$, increasing to $9.0 \%$ in patients older than 50 years. Per-polyp analysis showed the typical SSA/P was sessile or flat, $5 \mathrm{~mm}$ in size and located in the right colon. The higher prevalence of SSA/Ps in this study was favored by involvement of an expert pathologist, high adenoma detection rate (ADR) (median 38.5\%) amongst endoscopists, and good quality bowel preparation (median Boston Bowel Preparation score, $8 ; 90 \% \geq 6$ ), signifying the importance of pairing both quality indicators of colonoscopy and pathological expertise in the diagnosis of these lesions. ${ }^{16}$

Despite an overall improvement in recognition of SSA/Ps, wide variation in SSA/P detection rates amongst endoscopists is reported by some studies. ${ }^{16-18}$ For example in the aforementioned study by Ijspeert et al. ${ }^{16}$ the SSA/P detection rate ranged between 2.5\% and 13.6\%. A similar SSA/P detection range (1\% to $18 \%$ ) was reported in another study involving tertiary center gastroenterologists, with the odds of detecting at least one proximal serrated polyp for individual endoscopists ranging from 0.05 to 0.67 compared to the highest level detector. ${ }^{17}$ Misclassification of these lesions amongst pathologists could account for some of this difference. In a study of 1,910 average risk patients undergoing screening colonoscopy, the prevalence of SSA/ Ps rose from $1.5 \%$ to $8.1 \%$ after all polyps in the serrated class were reassessed by an expert pathologist. ${ }^{19}$ A multicenter study of 350 serrated polyps from 5,778 detected lesions, found the number of serrated lesions per colonoscopy ranged between 0.00 and 0.11 , with some centers' pathologists having never identi- fied proximal serrated lesions as SSA/Ps. ${ }^{20}$ These data suggest enhanced awareness, education and training are necessary for both endoscopists and pathologists alike to improve outcomes in these areas.

SSA/Ps are also associated with synchronous advanced neoplasia in the colon. ${ }^{13,21-25}$ In an early study of 3,121 asymptomatic patients undergoing screening colonoscopy, those with at least one proximal serrated polyp were more likely than those without, to have synchronous advanced neoplasia (17.3\% vs 10.0\%; odds ratio [OR], 1.90; 95\% confidence interval [CI], 1.33 to 2.70), particularly in patients with serrated polyps $\geq 10 \mathrm{~mm}$ in size (OR, 3.14; 95\% CI, 1.59 to 6.20). ${ }^{21}$ Furthermore detection of proximal serrated polyps at baseline examination was associated with an increased risk of interval neoplasia on subsequent surveillance colonoscopy. ${ }^{21}$ Other subsequent large studies have reported similar findings. ${ }^{13,22,24}$ Recently, a systematic review and meta-analysis of nine studies with 34,084 participants and overall serrated polyp prevalence of $15.6 \%$ showed that serrated polyps were associated with a more than 2-fold increased risk of detection of synchronous advanced neoplasia (OR, 2.05; 95\% CI, 1.38 to 3.04$).^{25}$ Individuals with proximal and large serrated polyps had the highest risk (OR, 2.77; 95\% CI, 1.71 to 4.46 and OR, 4.10; 95\% CI, 2.69 to 6.26, respectively). ${ }^{25}$ Thus, there is strong data supporting carefully searching for synchronous lesions whenever an SSA/P is detected, and particularly if it is large.

SSA/Ps are associated with increased risk for CRC, including interval cancers. ${ }^{2,26-28}$ Approximately 30\% of all CRC is believed to develop along the serrated neoplasia pathway, ${ }^{2,29}$ and although polypectomy reduces CRC incidence, ${ }^{30,31}$ the imperfect protection of colonoscopy against right colon $\mathrm{CRC}^{32,33}$ may be accounted for by failed detection or inadequate resection of SSA/Ps. ${ }^{10}$ A recent Danish case-control study of 272,342 individuals and 2,045 cases of CRC showed those with a history of SSA/Ps had a significantly increased risk of CRC than patients without these polyps. ${ }^{27}$ The CRC risk was particularly elevated in patients with proximal SSA/Ps (OR, 12.42; 95\% CI, 4.88 to 31.58), SSA/Ps with dysplasia (OR, 4.76; 95\% CI, 2.59 to 8.73 ) and females with SSA/Ps (OR, 5.05; 95\% CI, 3.05 to 8.37). ${ }^{27}$ The CRC risk was significantly elevated for those patients with TSAs (OR, 4.84; 95\% CI, 2.36 to 9.93) and for conventional adenomas (OR, 2.51; 95\% CI, 2.25 to 2.80). ${ }^{27}$ Further implicating SSA/Ps, interval cancers also commonly occur in the right colon, ${ }^{32,34}$ have the CpG island methylator phenotype (CIMP) with microsatellite instability (MSI), and activating mutations of the BRAF gene more often than noninterval CRC. ${ }^{35}$

\section{SERRATED POLYPOSIS SYNDROME}

Serrated polyposis syndrome (SPS) is characterized by multiple, large and/or proximal serrated polyps. Diagnosis is based upon satisfaction of one or more of the following WHO criteria 
(1) at least five serrated polyps proximal to the sigmoid colon, two of which are larger than $10 \mathrm{~mm}$; (2) any number of serrated polyps proximal to the sigmoid colon in a patient with a first degree relative with SPS; or (3) greater than 20 serrated polyps of any size, distributed throughout the colon. ${ }^{36}$ Patients with SPS have an increased risk of CRC, with a recent study reporting a standard incidence ratio of CRC in patients with SPS of 18.72 (95\% CI, 6.87 to 40.74), and a lifetime CRC risk of up to $50 \% .^{37,38}$ Although SPS has features of being a hereditary condition including familial clustering and increased risk of CRC amongst relatives, no germline mutations have been identified. Nonetheless, screening colonoscopy is recommended for first degree relatives, beginning at 40 years of age or 10 years younger than the age at diagnosis of the youngest affected relative. ${ }^{2,39}$ Management strategies focus on completely resecting all proximal polyps followed by annual surveillance, ${ }^{39}$ although a consensus on risk-stratified management (e.g., based upon polyp burden, location, histology and presence of dysplasia) of SPS is still pending. Two recent multicenter series from Spanish and Dutch-British cohorts of patients with SPS managed by intensive endoscopic surveillance showed a 1.5\% to 1.9\% absolute 5-year CRC risk estimate, ${ }^{40,41}$ less than previously expected. These results indicate that in SPS patients without CRC, early recognition and treatment of serrated polyps is imperative, and that protection from CRC by colonoscopic surveillance in dedicated centers is feasible. ${ }^{42}$

\section{CHARACTERIZATION OF SESSILE SERRATED ADENOMAS}

\section{The serrated neoplasia pathway}

Carcinogenesis in SSA/Ps is believed to progress through a unique epigenetic pathway. This involves hypermethylation of $\mathrm{CpG}$ islands (CIMP) on the promotor regions of tumor suppres- sor genes, in which a cytosine (C) is followed by a guanine $(\mathrm{G})$ nucleotide linked by a phosphodiester bond (CpG). ${ }^{43}$ Epigenetic silencing of the DNA mismatch repair (MMR) gene MLH1 through promotor hypermethylation leads to the MSI phenotype, and leaves the cell vulnerable to mutations in genes controlling cell growth. ${ }^{44-46}$ Notably, although MLH1 methylation occurs in early SSA/Ps, only reduced or loss of gene expression, which requires extensive methylation, is associated with dysplasia and progression to malignancy. ${ }^{3}$ This is supported by the observation that variably decreased MLH1 expression is seen in dysplastic areas of SSA/Ps, with loss of expression in invasive MSI-high CRC. ${ }^{47}$ The CIMP status of a lesion can be determined by assessment of a panel of 5 or 6 MMR genes, in which promotor hypermethylation of three or more genes is considered CIMP-high. ${ }^{35} \mathrm{SSA} / \mathrm{Ps}$, especially those with dysplasia, are considered the probable precursors to sporadic CIMPhigh, MSI-high CRC given the similarities in their molecular profiles including hypermethylation of MMR genes MLH1, and of other tumor suppressor genes such as p16INK4a, IGFBP7 and MGMT. ${ }^{48-51}$ Activation of the BRAF oncogene (BRAF V600E mutation) is also a feature of the serrated neoplasia pathway ${ }^{52,53}$ and is closely associated with CIMP-high CRC. ${ }^{43,54} B R A F$ regulates cell proliferation, differentiation and survival, and is hypothesized to have a role in early serrated polyp development., ${ }^{4,55}$

\section{Histopathological features}

Sporadic serrated polyps are characterised by a serrated architecture of the epithelium that lines the colonic crypts, thought to result from decreased epithelial cell apoptosis. ${ }^{56}$ The subtypes of serrated lesions may be distinguished by the location and extent of the proliferative zone. ${ }^{29}$ The specific causes of these changes are presumed to result from epigenetic alterations in genes responsible for cell proliferation and differentiation,
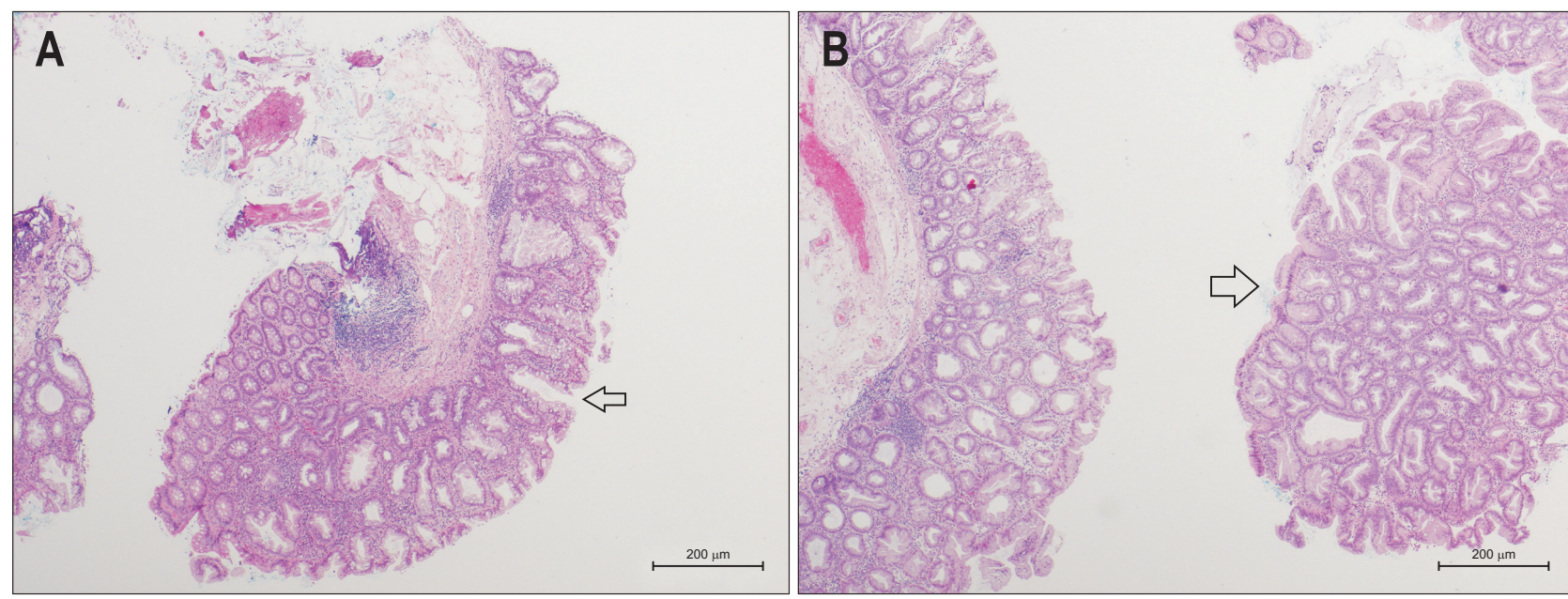

Fig. 1. Histologic features of sessile serrated adenomas/polyps (SSA/Ps). (A) A serrated adenoma (SSA/P) without dysplasia showing the classical features of broad bases and dilated crypts (arrow). H\&E stained, low power magnification. (B) An SSA/P with mild dysplasia is shown in the rightside specimen (arrow). The glandular architecture and surface epithelium of the dysplastic component resembles a conventional adenoma. The left-sided specimen is nondysplastic. H\&E stained, low power magnification. 
as well as genetic changes such as mutations in BRAF. ${ }^{2}$ SSA/ Ps are characterised by distorted crypt growth and dilatation of the crypt base, leading to the formation of 'boot' or ' $L$ ' or 'anchor'-shaped crypts (Fig. 1). ${ }^{2,6}$ The basal aspect of the crypt may contain hyper-serration, mature goblet cells and mucinous cells, which are responsible for the excessive mucin frequently seen within the dilated crypts and on the surface of the lesion. Recently, an expert consensus panel recommended that one unequivocal architecturally distorted crypt base was sufficient to diagnose an SSA/P. ${ }^{2}$ Pseudoinvasion below the muscularis mucosae, also known as displaced crypts, also often occurs in SSA/ Ps. ${ }^{57}$ SSA/Ps are not typically dysplastic, although cytological dysplasia resembling conventional adenoma with frequent loss of expression of MLH1 on immunohistochemistry may develop in some lesions and potentially progress quickly to invasive malignancy. ${ }^{3,14}$

\section{Endoscopic features of sessile serrated adenomas}

SSA/Ps are most commonly located in the right colon, have a sessile or flat morphology sometimes resembling prominent mucosal folds, pale in colour similar to the surrounding mucosa and with indistinct borders (Fig. 2). About two-thirds of lesions are covered by a tenacious mucous cap (Fig. 3), with less common signs including a rim of stool debris, alteration of fold contour, interrupted underlying mucosal pattern and a dome shaped protuberance. ${ }^{58}$ Because of these features, the endoscopic appearance of SSA/Ps may be subtle and even large lesions may be missed without careful attention from the endoscopist. It is prudent to note the location of the polyp before washing off the mucous cap as the SSA/P may be difficult to discern afterwards. ${ }^{2}$ Other factors associated with SSA/Ps include female sex, smokers with more than a 20 pack year history, diabetes and obesity. ${ }^{59,60}$

SSA/Ps are identified endoscopically by a Type II open-shape (II-0) pit pattern (sensitivity 65.5\%, specificity 97.3\% using magnification and indigo carmine chromoendoscopy). ${ }^{61}$ On narrow band imaging (NBI), other endoscopic predictors of SSA/Ps include a cloud-like surface, indistinct borders, irregular shape, and dark spots inside the crypts. ${ }^{62}$ A recent systematic review and meta-analysis assessing the utility of image enhanced endoscopy in differentiating SSA/Ps from nonneoplastic tissue showed $80 \%$ sensitivity for magnification-NBI, 60\% for NBI, $49 \%$ for autofluorescence, and 47\% for flexible spectral imaging color enhancement. ${ }^{63}$ In head to head comparisons with white light endoscopy (WLE), only NBI and magnification-NBI demonstrated significantly greater sensitivity. ${ }^{63}$ The NBI International Colorectal Endoscopic (NICE) classification based upon lesion colour, vessel appearance and surface pattern distinguishes
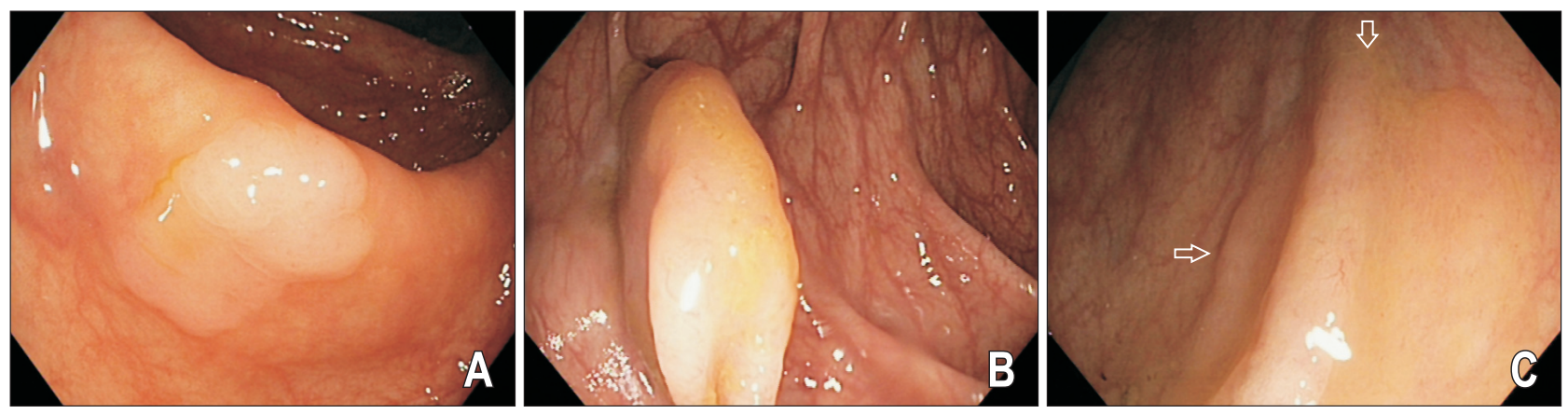

Fig. 2. (A-C) Endoscopic appearance of nondysplastic sessile serrated adenomas/polyps (SSA/Ps). SSA/Ps are often found in the right colon, are morphologically flat and pale, have a color similar to the surrounding mucosa and have indistinct borders (arrows). Detection requires good bowel preparation and a high index of suspicion.
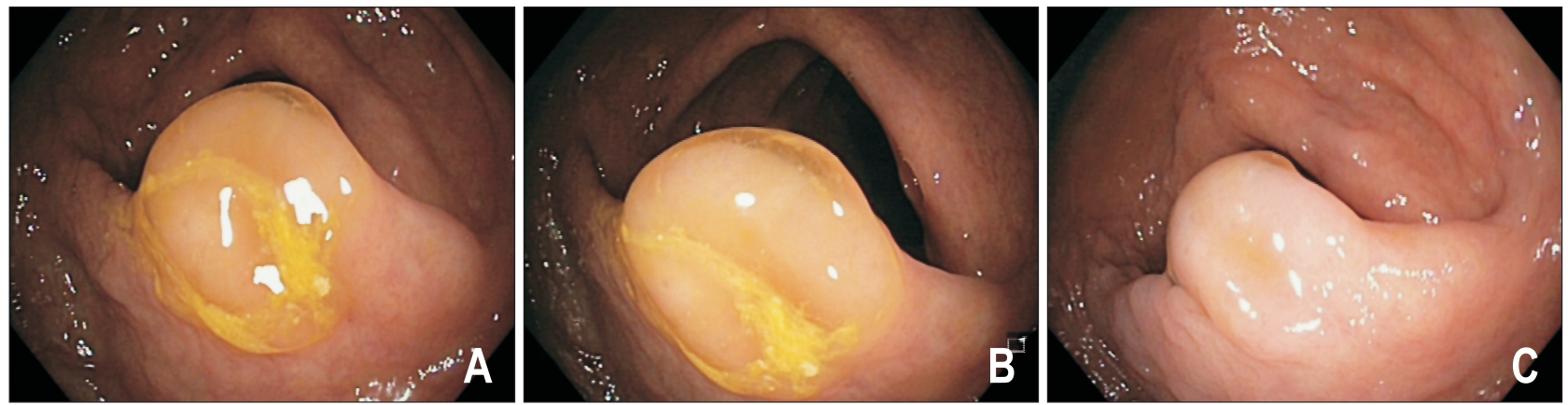

Fig. 3. Sessile serrated adenomas/polyp (SSA/P) before and after cleaning of the mucous cap. This nondysplastic SSA/P is covered by a tenacious mucous cap with a surrounding rim of stool (A, B). The lesion becomes less conspicuous (C) upon cleansing and can potentially be mistaken for a prominent mucosal fold. 
hyperplastic from adenomatous polyps, ${ }^{64}$ however, does not accurately diagnose SSA/Ps. ${ }^{65}$ To improve the endoscopic identification of SSA/Ps using NBI, the NICE classification was combined with the criteria for differentiation of SSA $/ \mathrm{Ps}^{62}$ to form the recently proposed Workgroup Serrated Polyps and Polyposis (WASP) classification. ${ }^{66}$ In the first validation phase using this classification, the accuracy of optical diagnosis for SSA/Ps versus non-SSA/Ps with high confidence amongst a cohort of 10 gastroenterologists was 0.83 (95\% CI, 0.75 to 0.91 ) rising to 0.93 (95\% CI, 0.87 to 0.98) after completion of a standardised WASP training module. ${ }^{66}$ Although promising, further validation of the WASP criteria in prospective trials is awaited before its routine implementation to daily practice. In practice and with experience, the recognition of SSA/Ps and their differentiation from adenomas is usually not challenging. ${ }^{67}$

Whereas nondysplastic SSA/Ps have a relatively homogeneous appearance, progression to more advanced lesions with dysplasia (SSA/P-D) is associated with accumulation of aberrant DNA methylation and additional lesion changes resembling that of a conventional adenoma (Fig. 4)..$^{61,67,68}$ The identification of an endoscopically apparent transition point between two differing surface patterns within a lesion should alert the endoscopist to an SSA/P harbouring dysplasia. The dysplastic component is usually a small ( 1 to $5 \mathrm{~mm}$ ) centrally or peripherally located nodule, and occasionally minimally elevated or depressed area within the lesion. ${ }^{67}$ Examination of the surface pit pattern with WLE and NBI often reveals two distinct patterns corresponding to the different histology, with the dysplastic component exhibiting a type III (tubular or roundish pits) or type IV (branched or gyrus-like pits) pattern. ${ }^{67}$ With NBI, the area of dysplasia is darker due to more abundant and thicker surface capillaries in keeping with a NICE 2 or Sano II vascular pattern, compared with the relatively hypovascular background pattern of the nondysplastic SSA/P. ${ }^{67}$ Once dysplasia develops, transformation to invasive cancer can be rapid and may occur even when lesions are small. ${ }^{67,69}$ Large ( $\geq 20 \mathrm{~mm}$ ) SSA/Ps may more frequently harbour dysplasia, and was present in $32.4 \%$ of all such lesions referred for endoscopic mucosal resection (EMR) in a prospective multicenter study of large laterally spreading lesions (LSLs). ${ }^{68}$ Multivariable analysis revealed SSA/P-D were significantly associated with increasing age (OR, 1.69 per decade; 95\% CI, 0.19 to 2.40), increasing lesion size (OR, 1.90 per $10 \mathrm{~mm}$; 95\% CI, 1.30 to 2.78), an "adenomatous" pit pattern (Kudo III, IV or V) (OR, 3.98; 95\% CI, 1.94 to 8.15 ) and any 0-Is component within an SSA/P (OR, 3.10; 95\% CI, 1.19 to 8.12). ${ }^{68}$

\section{DETECTION OF SESSILE SERRATED ADENOMAS}

Endoscopic detection of SSA/Ps can be assisted by high definition (HD) endoscopes, chromoendoscopy and/or image enhancement, adoption of quality criteria for colonoscopy and possibly use of ancillary devices. High definition scopes deliver better image quality and brighter illumination, and their use improves the detection of both adenomas and SSA/Ps. ${ }^{70}$ In another study, the combination of HD colonoscopes with chromoendoscopy (0.4\% indigo carmine) during scope withdrawal increased the overall detection rate for adenomas (0.95 vs 0.66 per patient) and serrated lesions ( 1.19 vs 0.49 per patient) $(\mathrm{p}<0.001)$
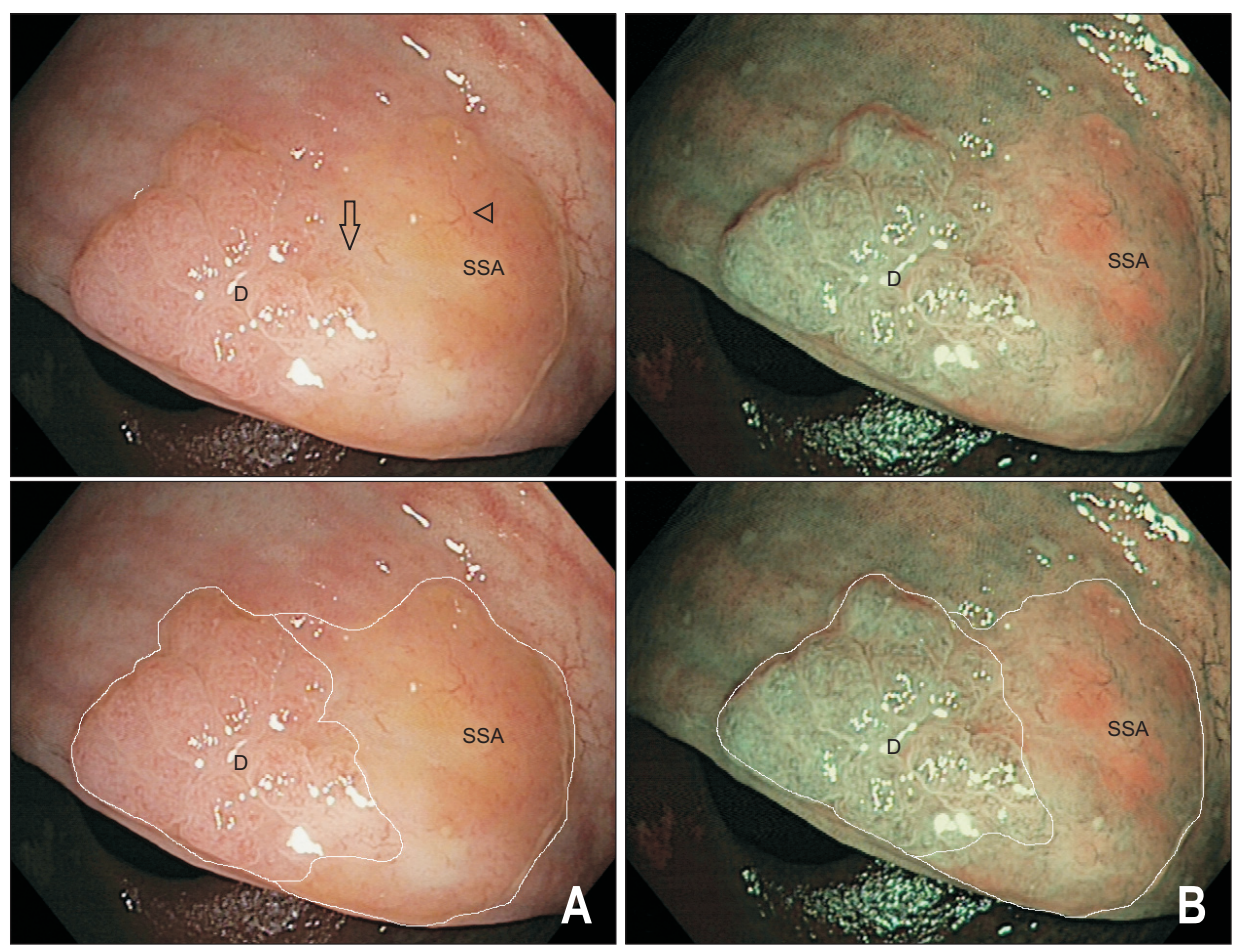

Fig. 4. Endoscopic appearance of sessile serrated adenomas/polyps (SSA/Ps) with dysplasia. A $20 \mathrm{~mm}$ SSA/P-D viewed under white light (A) and narrow band imaging (B) with and without the dysplastic (label D) and nondysplastic (label SSA) components outlined. The lesion has developed a raised, nodular component on the left-hand aspect with a type IV surface pit pattern indicative of dysplastic transformation (label D). The nondysplastic component of the lesion (label SSA) is pale with relatively hypovascular background surface markings and is covered by a thin layer of stool debris (arrowhead). Note there is an obvious transition zone from the nondysplastic flat SSA/P to the area of dysplasia (arrow). The lesion and a rim of normal tissue were removed en bloc by endoscopic mucosal resection; histology confirmed a completely resected SSA/P with mild dysplasia. 
compared with standard colonoscopy. ${ }^{71}$ Potential drawbacks included longer procedural times and additional cost of chromoendoscopic dye. The utility of NBI compared with HD-WLE for detecting serrated lesions was assessed in a randomized controlled trial of 800 patients. $^{72}$ Although more proximal colon serrated lesions were detected by NBI than HD-WLE (204 vs 158), this did not achieve statistical significance. ${ }^{72}$ Similarly, a randomized multicenter trial found no significant difference in polyp miss rates using HD-WLE or NBI in patients with SPS. ${ }^{73}$

The detection of SSA/Ps in CRC screening programs was assessed in a multicenter retrospective series of over 70,000 colonoscopies, reporting significant association with caecal intubation rate (OR, 3.75; 95\% CI, 2.22 to 6.34), presence of at least one advanced adenoma (OR, 2.08; 95\% CI, 1.86 to 2.33) and $\mathrm{ADR}^{74}$ In this study, no association between faecal immunochemical test (FIT) and detection of SSA/Ps was found. ${ }^{74}$ Similar outcomes were reported from a prospective population screening study of over 6,000 patients, finding FIT detected SSA/Ps with significantly lower sensitivity than conventional adenomas. ${ }^{75}$ In a multicenter study of almost 8,000 colonoscopies, serrated polyp detection increased with each minute of withdrawal time above 6 minutes, with maximal benefit at 9 minutes (incident rate ratio, $1.77 ; 95 \% \mathrm{CI}, 1.15$ to 2.72 ). ${ }^{76}$ Other studies have also demonstrated the benefits of a longer withdrawal technique, ${ }^{18}$ including second looks and retroflexion in the right colon, ${ }^{77}$ with careful cleaning and meticulous mucosal examination for the detection of SSA/Ps.

Adequacy of bowel preparation is well documented for optimising detection of conventional adenomas as well as for SSA/ Ps. One study reported overall SSA/P detection of $4.6 \%$ versus $12.0 \%$ (OR, 0.37; 95\% CI, 0.15 to 0.87 ) and $1.5 \%$ versus $7.9 \%$ (OR, 0.19 ; $95 \% \mathrm{CI}, 0.05$ to 0.81 ) in the right colon for intermediate quality preparation versus high quality preparation, respectively. ${ }^{78}$ This study also showed that any level of preparation below high quality was associated with a significant decrease in SSA/ $\mathrm{P}$ detection, whereas intermediate quality preparation was still adequate for adenoma detection. ${ }^{78}$ Split dose bowel preparation improves colonic cleansing and detection of conventional adenomas. ${ }^{79,80}$ In a prospective randomised trial of 341 patients, split dose bowel preparation also improved SSA/Ps detection relative to single dose regimens ( $9.9 \%$ vs $2.4 \%, \mathrm{p}=0.004)$, with improved patient tolerance and quality of preparation. ${ }^{81}$

Ancillary devices used with the aim of improving mucosal examination and polyp detection include disposable attachments to the colonoscope such as transparent caps and Endocuff (ARC Medical Design, Leeds, UK), accessory video processors such as Third Eye ${ }^{\circledR}$ Retroscope $^{\circledR}$ and Third Eye ${ }^{\circledR}$ Panoramic $^{\mathrm{TM}}$ (Avantis Medical Systems, Sunnyvale, CA, USA), and specialised colonoscopes such as Full Spectrum Endoscopy ${ }^{\circledR}$ (EndoChoice Inc., Alpharetta, GA, USA), Extra-Wide-Angle-View colonoscope (Olympus, Tokyo, Japan), NaviAid ${ }^{\mathrm{TM}}$ G-EYE ${ }^{\mathrm{TM}}$ balloon colonoscope (SMART Medical Systems Ltd., Ra'anana, Israel). ${ }^{82-84}$ Distal attachment caps have not demonstrated improved polyp detection, ${ }^{85}$ whereas the others have shown promise but are either technically intensive and/or associated with significant additional cost. A recent review based on observational data suggested use of Endocuff may result in higher ADR (35.4\% to $53.5 \%$ ), particularly for polyp detection in the right colon. ${ }^{83}$ However, a multicenter randomised trial did not demonstrate Endocuff identified an increased number of patients with one or more adenomas relative to conventional colonoscopy. ${ }^{86}$ Taking everything together, meticulous examination technique, high quality bowel preparation and use of HD scopes remain the key to optimising SSA/P detection. Endoscopists with high ADRs are unlikely to gain significant improvements in ADR by using the additional technologies and ancillary devices currently available.

\section{RESECTION OF SESSILE SERRATED ADENOMAS}

Complete polyp resection is the fundamental principle governing treatment of SSA/Ps. All serrated lesions except for diminutive rectosigmoid lesions should be removed. ${ }^{2}$ However, endoscopic detection and resection of SSA/Ps is hampered by their predominantly flat morphology, inconspicuous surface features and indistinct borders. Once detected, these lesions can be excised endoscopically utilizing similar principles to those for resection of conventional adenomas. The Complete Adenoma Resection (CARE) study assessed the incomplete resection rate (IRR) of polyps by immediate biopsy of the resection margins in 1,427 patients undergoing colonoscopy with at least one nonpedunculated polyp. The study found that SSA/Ps were more likely to be incompletely resected than conventional adenomas (31\% vs $7.2 \%, p<0.001$ ), and that the IRR rose to $47.6 \%$ for larger ( 10 to $20 \mathrm{~mm}$ ) SSA/Ps. ${ }^{10}$ In this study, the two strongest associations for IRR were increasing polyp size (relative risk [RR], 2.1; 95\% CI, 1.13 to 3.86 for lesions $10-20 \mathrm{~mm}$ vs $5-9 \mathrm{~mm}$ ), and SSA/P diagnosis (RR, 3.74; 95\% CI, 2.04 to 6.84). ${ }^{10}$ Significant variation in rates of complete resection were also observed amongst endoscopists, ${ }^{10}$ indicating that careful attention to polypectomy technique is essential to achieving satisfactory outcomes, and particularly for SSA/Ps.

\section{Removal of small sessile serrated adenomas ( $<10 \mathrm{~mm})$}

Cold snare polypectomy (CSP), when performed correctly, is ideal for removal of diminutive and small SSA/Ps up to $10 \mathrm{~mm}$ in size, due to its efficacy and safety. ${ }^{87-89}$ CSP is superior to cold forceps polypectomy with regard to completeness of excision of small and diminutive polyps. ${ }^{88-90}$ Hot forceps polypectomy is associated with high rates of deep tissue injury, poor histological specimens, residual tissue, and is now strongly discouraged. ${ }^{91,92}$ The principle of CSP is to ensure that complete polyp removal 
is achieved with a 1 to $2 \mathrm{~mm}$ margin of normal tissue..$^{92,93}$ Our recommended approach to CSP is described in Table 2.

The efficacy of CSP using thin wire snares has been assessed by a number of studies, although none have solely included SSA/Ps. In one study, completeness of excision based on endoscopic imaging was significantly higher with thin wire $(0.30 \mathrm{~mm})$ than thick wire $(0.47 \mathrm{~mm})$ snares $(90.2 \%$ vs $73.3 \%$, $\mathrm{p}<0.05)$, with a trend towards higher complete pathological excision (73.3\% vs 65.2\%, $\mathrm{p}=0.4$ ). ${ }^{94}$ Another prospective randomized controlled trial of 210 lesions resected by CSP found complete pathological resection was significantly greater with thin wire than thick wire snares ( $91 \%$ vs 79\%, $\mathrm{p}=0.015$ ), particularly for polyps 8 to $10 \mathrm{~mm}$ in size. ${ }^{95}$

The risk of complications related to CSP such as perforation and clinically significant bleeding is extremely low. ${ }^{87}$ The rate of perforation is negligible as the closed snare is unable to cut through muscularis propria, and its occurrence has mostly been associated with lesions removed using electrocautery (hot snare polypectomy, HSP). ${ }^{96,97}$ Furthermore, compared with HSP, CSP has similar rates of complete polyp resection, shorter procedure time and no increase in clinically significant bleeding. ${ }^{98-100}$ Protrusions within the cold snare defect occur in approximately one in six cases, and may create concern for incomplete resection, however, these do not contain residual polyp nor are they associated with adverse outcomes. ${ }^{101}$ Immediate bleeding after CSP is common, but is typically self-limited and without risk of ongoing or delayed bleeding. ${ }^{99}$

\section{Removal of large sessile serrated adenomas (10-20 mm)}

EMR is the first-line therapy for LSLs. The supporting data is mostly based on resection of conventional adenomas, ${ }^{92,102,103}$ however, studies have also shown large ( $\geq 10 \mathrm{~mm}$ ) SSA/Ps can be adequately treated by EMR (Fig. 5). ${ }^{104-107}$ HSP is highly operator dependant and may be inadequate for resection of SSA/
Ps. For example, the CARE study showed wide inter-operator variability in efficacy of HSP with almost half of the lesions 10 to $20 \mathrm{~mm}$ in size incompletely resected using this technique. ${ }^{10}$ Large SSA/Ps are also more likely to harbor dysplasia, which may be subtle, and these lesions should be carefully examined prior to removal, particularly with respect to their surface pattern and peripheral extent, to ensure complete resection. As mentioned above, dysplasia is manifest as a transition point with a change in surface appearance from the usual flat SSA/ $P$ morphology to a nodular or minimally elevated or depressed area within the lesion, along with an "adenomatous" (type IIIIV) pit pattern. ${ }^{67}$ The safety and efficacy of endoscopic resection for large SSA/Ps was demonstrated in a 2 center retrospective study of 199 patients with 251 proximal colon SSA/Ps measuring $10 \mathrm{~mm}$ or larger removed by EMR. ${ }^{104}$ After mean follow-up of $17.8 \pm 15.4$ months, five patients (3.6\%; 95\% CI, 0.5\% to 6.7\%) developed local recurrence with a median size of $4 \mathrm{~mm} .{ }^{104}$ The recurrences were all cured endoscopically. There were no complications and no high grade dysplasia or advanced CRC following the index colonoscopy. ${ }^{104}$

The median size of large SSA/Ps tend to be smaller than that of adenomatous LSLs. SSA/Ps seem to be relatively loosely attached to the deeper mural layers, usually lift easily and are not associated with submucosal fibrosis. ${ }^{107}$ As such, SSA/Ps are generally easier to remove by EMR than adenomatous LSLs. Nonetheless, EMR is associated with risks such as perforation ( $1 \%$ to $2 \%$ ), post polypectomy syndrome $(0.5 \%)$ and clinically significant post EMR bleeding (6\% to $11 \%$ ). ${ }^{102,108-110}$ Therefore, it may be beneficial to remove large SSA/Ps by piecemeal CSP, achieving complete excision whilst mitigating many of the adverse effects of EMR (Fig. 6). In a pilot study of 15 patients with adenomatous colonic polyps (mean size, $20 \mathrm{~mm}$; range, 10 to $45 \mathrm{~mm}$ ) removed by piecemeal CSP using a stiff thin wire snare, technical success was $100 \%$, with no perforation, no post pol-

Table 2. Technical Tips for the Removal of SSA/Ps (<10 mm) by Cold Snare Polypectomy

1. Position the lesion in the 5 to 6 o'clock position.

2. Place the catheter of the opened snare on normal mucosa 1 to $2 \mathrm{~mm}$ distal to the lesion with the snare tip 1 to $2 \mathrm{~mm}$ proximal to the lesion. Stiff thin-wire snares are likely more effective.

3. Anchor the catheter in place on the mucosa by downward angulation of the scope tip (pushing forward on the up/down wheel).

4. Close the snare, capturing the polyp with a margin of normal tissue. Avoid excessive distention of the colon as tension on the wall will cause the closing snare to slide over the mucosa, impeding tissue capture. If this occurs, gently deflating the lumen during snare closure may be helpful.

5. Small flat nonpolypoid lesions (Paris 0-IIa and 0-IIb morphology) can be difficult to capture. A suction pseudopolyp technique, whereby the lesion is aspirated into the suction channel of the colonoscope and continuous suction applied for 5 seconds whilst the colonoscope is gently retracted, allows formation of a pseudopolyp to facilitate subsequent resection. This has been shown to be a safe, effective and reproducible therapy for removal of these lesions. ${ }^{11,112}$

6. Expand the mucosal defect following polypectomy by water jet irrigation. This distends the defect and its edges, facilitating inspection for residual polyp tissue.

SSA/Ps, sessile serrated adenoma/polyps. 

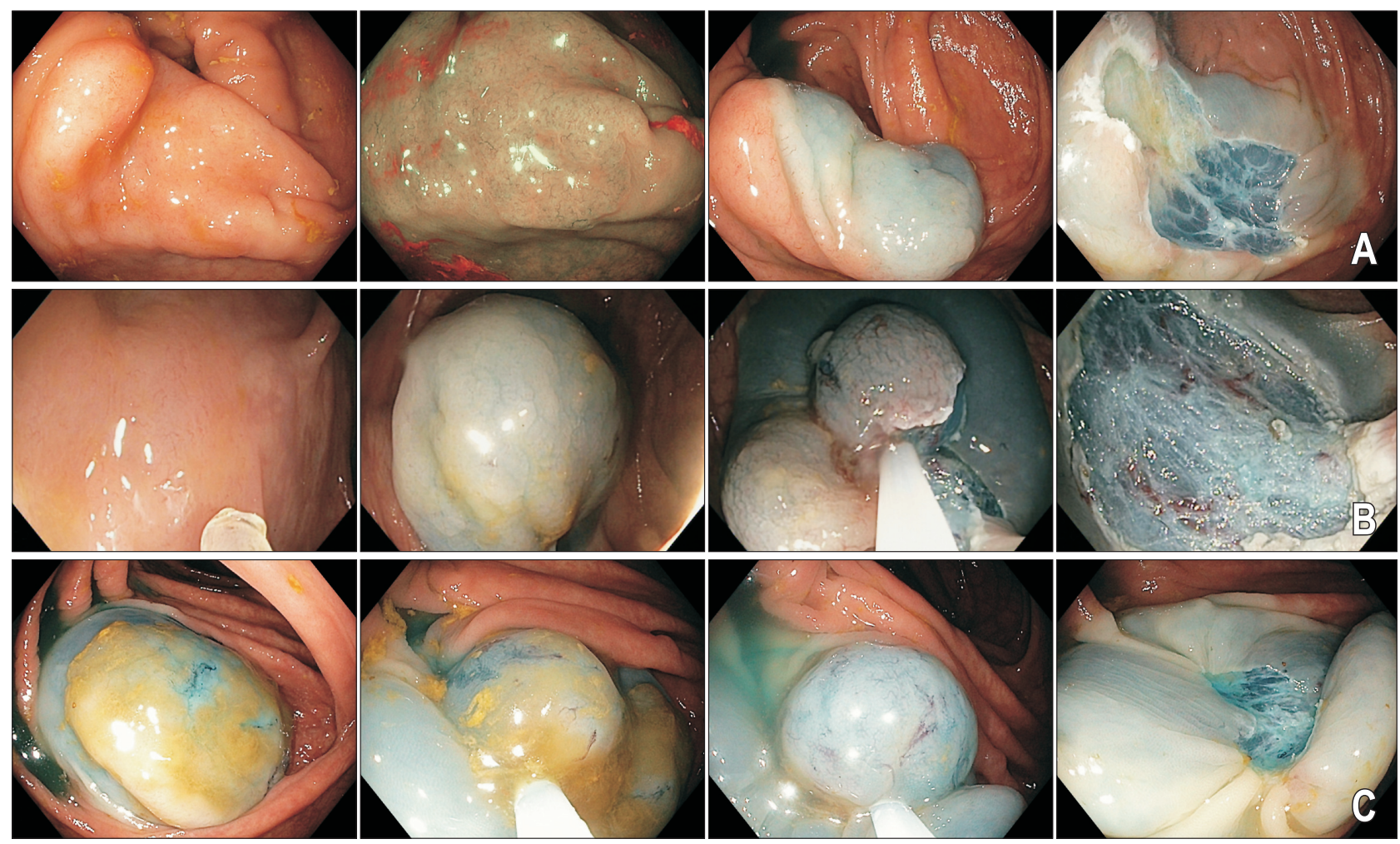

Fig. 5. Endoscopic mucosal resection of sessile serrated adenomas/polyps (SSA/Ps). (A-C) Note the inconspicuous appearance of all three lesions despite their larger sizes. Submucosal chromogelofusine injection assists with delineating the peripheral extent of the lesion. A margin of normal tissue should be captured during mucosal resection. Thermal ablation of the resection margins with snare tip soft coagulation (effect 4, 80W; VIO 300D; Erbe) reduces the risk of lesion recurrence.
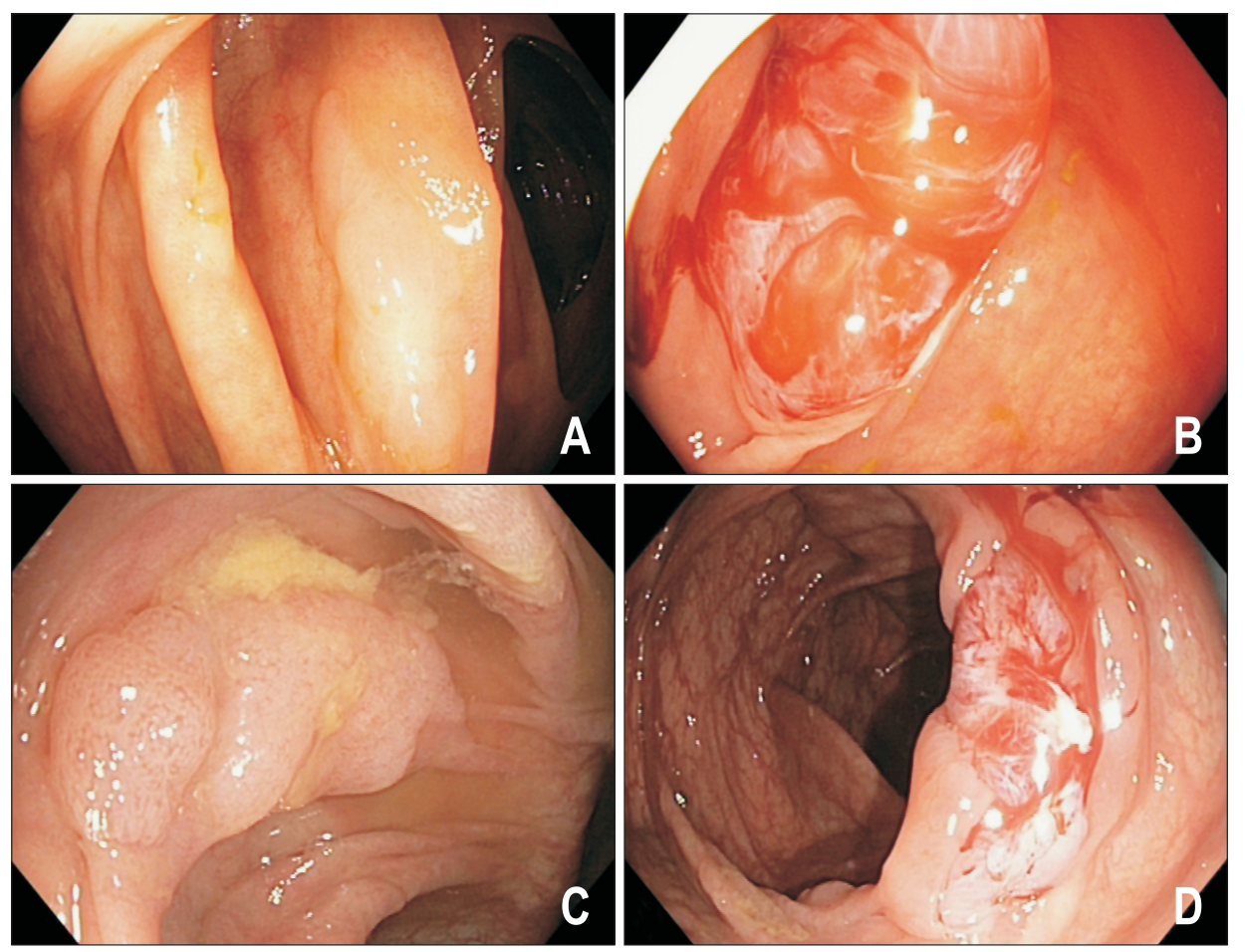

Fig. 6. Piecemeal cold snare polypectomy of sessile serrated adenomas/polyp (SSA/P). Larger (10 to $15 \mathrm{~mm}$ ) SSA/Ps (A, C) removed by piecemeal cold snare polypectomy $(\mathrm{B}, \mathrm{D})$. 
ypectomy syndrome and only one delayed bleeding episode in a patient on warfarin. ${ }^{113}$ A subsequent study involving 30 sessile colonic polyps $\geq 10 \mathrm{~mm}$ in size treated by piecemeal CSP also found this technique to be feasible, with no significant adverse events. ${ }^{114}$ At first follow-up after 6 months, 20\% of patients had small volume residual tissue, and all cases were treated endoscopically. ${ }^{114}$ Although piecemeal CSP appears effective and safe for resection of large SSA/Ps, particularly those 10 to $20 \mathrm{~mm}$ in size, prospective studies are awaited to determine the long term durability of this technique, and whether risks of complications such as bleeding are truly reduced.

\section{Removal of larger sessile serrated adenomas (>20 mm)}

EMR of larger SSA/Ps ( $>20 \mathrm{~mm}$ ) is safe and effective, with comparable recurrence rates to that seen with similar sized conventional adenomas (8.7\% vs $11.1 \%, \mathrm{p}=0.8) .{ }^{105} \mathrm{~A}$ recent multicenter, prospective cohort of 2,000 LSLs $\geq 20 \mathrm{~mm}$ (median size $35 \mathrm{~mm}$ ) comprising $323 \mathrm{SSA} / \mathrm{Ps}$ and 1,527 adenomas, showed large SSA/Ps could be successfully removed by EMR in almost all cases. ${ }^{107}$ The study reported EMR of these lesions compared with adenomatous LSLs, was easier to perform, with less intraprocedural bleeding and similar rates of significant adverse events. ${ }^{107}$ Cumulative recurrence rates at 6 and 12 months for SSA/Ps was significantly less compared with adenomas (6.3\% and $7.0 \%$ vs $16.1 \%$ and $20.4 \%, p<0.001$, respectively). Subgroup analysis by lesion size revealed an 8-fold increased risk of recurrence for 20 to $25 \mathrm{~mm}$ adenomatous LSLs versus SSA/ Ps, but no significant difference in risk between lesion types in larger lesion groups. ${ }^{107}$ The technique of EMR for removal of LSLs including large SSA/Ps has been described, ${ }^{92,115,116}$ and key aspects are summarized in Table $3 .^{117,118}$

\section{SURVEILLANCE}

Recommendations for colonoscopy surveillance intervals in patients with SSA/Ps follow similar principles to that of conventional adenomas, and are based upon lesion number, size and histology, albeit with some caveats. Although guidelines exist, ${ }^{2,39,119}$ these are largely based upon observational data and expert opinion, as prospective, controlled data on the natural history of SSA/Ps is lacking. Major European and North American societal guidelines are largely congruent and recommend the following intervals of colonoscopy surveillance: 5 years for patients with a single SSA/P without dysplasia $<10 \mathrm{~mm}$ in size, 3 to 5 years for patients with $<3$ SSA/Ps without dysplasia each $<10 \mathrm{~mm}$ in size, 3 years for patients with $\geq 3$ SSA/Ps without dysplasia each $<10 \mathrm{~mm}$ in size, and 3 years for patients with "high risk" lesions (any lesion $\geq 10 \mathrm{~mm}$ in size or with dysplasia). ${ }^{39,119}$ Lesions removed piecemeal may warrant early followup colonoscopy at 6 months given the potential for incomplete resection, although this area requires much further systematic study to optimise techniques and quantitate the risks.

Recent expert consensus guidelines advocate a slightly more aggressive surveillance recommendation, suggesting an interval colonoscopy in 1 to 3 years after resection of any SSA/P with dysplasia or after resection of $\geq 2 \mathrm{SSA} / \mathrm{Ps}$ of $\geq 10 \mathrm{~mm}$ in size. ${ }^{2}$ These recommendations are based upon the observation that interval CRC are more likely right sided, colonoscopy is less effective at preventing proximal CRC, and the greater variability in detection of SSA/Ps compared with conventional adenomas. ${ }^{2}$ Other guidelines do not make any specific recommendations with respect to serrated lesions, instead treating such lesions the same as conventional adenomas. ${ }^{120}$

\section{CONCLUSIONS}

As our understanding of the biological behaviour of SSA/ Ps improves, we increasingly recognise the clinical significance of these lesions, in particular their potential to progress to CRC and role in development of interval cancers. SSA/Ps can be

Table 3. Technical Tips for the Removal of larger SSA/Ps by Endoscopic Mucosal Resection

1. Carefully inspect the lesion for features of dysplasia and peripheral extent. Use of high definition scopes with or without chromoendoscopy or NBI may assist. Dye based submucosal lift solution for EMR aids in delineating the lesion's peripheral extent. ${ }^{107}$

2. Ensure snare captures a peripheral rim of 1 to $2 \mathrm{~mm}$ normal mucosal tissue around the polyp. Utilize EMR rather than hot snare polypectomy for SSA/Ps 10 to $20 \mathrm{~mm}$ as this has higher rates of complete polyp resection. Piecemeal cold snare polypectomy is an alternative technique.

3. Firmly anchor the snare catheter in normal tissue 1 to $2 \mathrm{~mm}$ front of the polyp, and allow the polyp to fall into the open snare by deflating the lumen. With further deflation, close the snare to capture the polyp, but do not close completely.

4. At this point, we prefer to take control of the snare from the assistant, closing to within $1 \mathrm{~cm}$. Mobility of the captured tissue relative to the adjacent bowel wall is assessed, followed by tissue resection with electrocautery (EndoCut Q, effect 3, cut duration 1, cut interval 6; VIO 300D; Erbe).

5. Carefully assess the resection margins to assess for residual polyp. Defect expansion with water jet irrigation may assist inspection. Residual polyp can be subtle and further resections can be performed to remove suspect tissue.

6. Recurrence after EMR can be reduced by ablating the resection margins with snare tip soft coagulation (effect 4, 80W) by a light touch technique. 7. Referral to a center with expertise in advanced polypectomies is recommended if there is insufficient local expertise in EMR. ${ }^{117,118}$

SSA/Ps, sessile serrated adenoma/polyps; NBI, narrow band imaging; EMR, endoscopic mucosal resection. 
difficult to identify and use of $\mathrm{HD}$ colonoscopes, quality bowel preparation, meticulous mucosal examination and withdrawal technique are the factors most likely to improve their detection. Each lesion should be carefully assessed to determine its peripheral extent and localise any dysplastic areas. Like all adenomatous colorectal polyps, complete endoscopic resection is the key to successful eradication of SSA/Ps. Lesions $\leq 10 \mathrm{~mm}$ in size are suitable for removal by CSP. Lesions 10 to $20 \mathrm{~mm}$ in size may be removed by either piecemeal CSP or EMR. Larger lesions are currently best removed by EMR. Improved detection, accurate characterisation and safe and complete resection of SSA/Ps are imperative to optimising patient outcomes and reducing the incidence of CRC.

\section{CONFLICTS OF INTEREST}

No potential conflict of interest relevant to this article was reported.

\section{REFERENCES}

1. Bosman FT, Carneiro F, Hruban RH, Theise ND. WHO classification of tumours of the digestive system. Lyon: IARC Press, 2010.

2. Rex DK, Ahnen DJ, Baron JA, et al. Serrated lesions of the colorectum: review and recommendations from an expert panel. Am J Gastroenterol 2012;107:1315-1329.

3. Yang HM, Mitchell JM, Sepulveda JL, Sepulveda AR. Molecular and histologic considerations in the assessment of serrated polyps. Arch Pathol Lab Med 2015;139:730-741.

4. IJspeert JE, Vermeulen L, Meijer GA, Dekker E. Serrated neoplasia-role in colorectal carcinogenesis and clinical implications. Nat Rev Gastroenterol Hepatol 2015;12:401-409.

5. Obuch JC, Pigott CM, Ahnen DJ. Sessile serrated polyps: detection, eradication, and prevention of the evil twin. Curr Treat Options Gastroenterol 2015;13:156-170.

6. Crockett SD, Snover DC, Ahnen DJ, Baron JA. Sessile serrated adenomas: an evidence-based guide to management. Clin Gastroenterol Hepatol 2015;13:11-26.

7. Bouwens MW, van Herwaarden YJ, Winkens B, et al. Endoscopic characterization of sessile serrated adenomas/polyps with and without dysplasia. Endoscopy 2014;46:225-235.

8. Burgess NG, Tutticci NJ, Pellise M, Bourke MJ. Sessile serrated adenomas/polyps with cytologic dysplasia: a triple threat for interval cancer. Gastrointest Endosc 2014;80:307-310.

9. Kaminski MF, Regula J, Kraszewska E, et al. Quality indicators for colonoscopy and the risk of interval cancer. N Engl J Med 2010;362:1795-1803.

10. Pohl H, Srivastava A, Bensen SP, et al. Incomplete polyp resection during colonoscopy-results of the complete adenoma resection (CARE) study. Gastroenterology 2013;144:74-80.

11. Hetzel JT, Huang CS, Coukos JA, et al. Variation in the detection of serrated polyps in an average risk colorectal cancer screening cohort. Am J Gastroenterol 2010;105:2656-2664.

12. Sanaka MR, Gohel T, Podugu A, et al. Adenoma and sessile serrated polyp detection rates: variation by patient sex and colonic segment but not specialty of the endoscopist. Dis Colon Rectum 2014;57:1113-1119.

13. Hazewinkel Y, de Wijkerslooth TR, Stoop EM, et al. Prevalence of serrated polyps and association with synchronous advanced neoplasia in screening colonoscopy. Endoscopy 2014;46:219-224.

14. Lash RH, Genta RM, Schuler CM. Sessile serrated adenomas: prevalence of dysplasia and carcinoma in 2139 patients. J Clin Pathol 2010;63:681-686.

15. Kumbhari V, Behary J, Hui JM. Prevalence of adenomas and sessile serrated adenomas in Chinese compared with Caucasians. J Gastroenterol Hepatol 2013;28:608-612.

16. IJspeert JE, de Wit K, van der Vlugt M, Bastiaansen BA, Fockens $\mathrm{P}$, Dekker E. Prevalence, distribution and risk of sessile serrated adenomas/polyps at a center with a high adenoma detection rate and experienced pathologists. Endoscopy 2016;48:740-746.

17. Kahi CJ, Hewett DG, Norton DL, Eckert GJ, Rex DK. Prevalence and variable detection of proximal colon serrated polyps during screening colonoscopy. Clin Gastroenterol Hepatol 2011;9:42-46.

18. de Wijkerslooth TR, Stoop EM, Bossuyt PM, et al. Differences in proximal serrated polyp detection among endoscopists are associated with variability in withdrawal time. Gastrointest Endosc 2013;77:617-623.

19. Abdeljawad K, Vemulapalli KC, Kahi CJ, Cummings OW, Snover DC, Rex DK. Sessile serrated polyp prevalence determined by a colonoscopist with a high lesion detection rate and an experienced pathologist. Gastrointest Endosc 2015;81:517-524.

20. Payne SR, Church TR, Wandell M, et al. Endoscopic detection of proximal serrated lesions and pathologic identification of sessile serrated adenomas/polyps vary on the basis of center. Clin Gastroenterol Hepatol 2014;12:1119-1126.

21. Schreiner MA, Weiss DG, Lieberman DA. Proximal and large hyperplastic and nondysplastic serrated polyps detected by colonoscopy are associated with neoplasia. Gastroenterology 2010;139:1497-1502.

22. Alvarez C, Andreu M, Castells A, et al. Relationship of colonoscopy-detected serrated polyps with synchronous advanced neoplasia in average-risk individuals. Gastrointest Endosc 2013;78:333341.

23. Li D, Jin C, McCulloch C, et al. Association of large serrated polyps with synchronous advanced colorectal neoplasia. Am J Gastroenterol 2009;104:695-702.

24. Ng SC, Ching JY, Chan VC, et al. Association between serrated polyps and the risk of synchronous advanced colorectal neoplasia in average-risk individuals. Aliment Pharmacol Ther 2015;41:108-115.

25. Gao Q, Tsoi KK, Hirai HW, et al. Serrated polyps and the risk of synchronous colorectal advanced neoplasia: a systematic review and meta-analysis. Am J Gastroenterol 2015;110:501-509.

26. Vu HT, Lopez R, Bennett A, Burke CA. Individuals with sessile 
serrated polyps express an aggressive colorectal phenotype. Dis Colon Rectum 2011;54:1216-1223.

27. Erichsen R, Baron JA, Hamilton-Dutoit SJ, et al. Increased risk of colorectal cancer development among patients with serrated polyps. Gastroenterology 2016;150:895-902.

28. Holme 0, Bretthauer M, Eide TJ, et al. Long-term risk of colorectal cancer in individuals with serrated polyps. Gut 2015;64:929936.

29. Snover DC. Update on the serrated pathway to colorectal carcinoma. Hum Pathol 2011;42:1-10.

30. Winawer SJ, Zauber AG, Ho MN, et al. Prevention of colorectal cancer by colonoscopic polypectomy: the National Polyp Study Workgroup. N Engl J Med 1993;329:1977-1981.

31. Zauber AG, Winawer SJ, O'Brien MJ, et al. Colonoscopic polypectomy and long-term prevention of colorectal-cancer deaths. $\mathrm{N}$ Engl J Med 2012;366:687-696.

32. Singh H, Nugent Z, Demers AA, Kliewer EV, Mahmud SM, Bernstein $\mathrm{CN}$. The reduction in colorectal cancer mortality after colonoscopy varies by site of the cancer. Gastroenterology 2010;139:1128-1137.

33. Brenner H, Chang-Claude J, Seiler CM, Rickert A, Hoffmeister M. Protection from colorectal cancer after colonoscopy: a population-based, case-control study. Ann Intern Med 2011;154:22-30.

34. Baxter NN, Goldwasser MA, Paszat LF, Saskin R, Urbach DR, Rabeneck L. Association of colonoscopy and death from colorectal cancer. Ann Intern Med 2009;150:1-8.

35. Arain MA, Sawhney M, Sheikh S, et al. CIMP status of interval colon cancers: another piece to the puzzle. Am J Gastroenterol 2010;105:1189-1195.

36. Snover D. Serrated polyps of the colon and rectum and serrated polyposis. 4th ed. Lyon: IARC, 2010.

37. Edelstein DL, Cruz-Correa M, Soto-Salgado M, et al. Risk of colorectal and other cancers in patients with serrated polyposis. Clin Gastroenterol Hepatol 2015;13:1697-1699.

38. Edelstein DL, Axilbund JE, Hylind LM, et al. Serrated polyposis: rapid and relentless development of colorectal neoplasia. Gut 2013;62:404-408.

39. Lieberman DA, Rex DK, Winawer SJ, et al. Guidelines for colonoscopy surveillance after screening and polypectomy: a consensus update by the US Multi-Society Task Force on Colorectal Cancer. Gastroenterology 2012;143:844-857.

40. IJspeert JE, Rana SA, Atkinson NS, et al. Clinical risk factors of colorectal cancer in patients with serrated polyposis syndrome: a multicenter cohort analysis. Gut 2017;66:278-284.

41. Carballal S, Rodríguez-Alcalde D, Moreira L, et al. Colorectal cancer risk factors in patients with serrated polyposis syndrome: a large multicenter study. Gut 2016;65:1829-1837.

42. Hassan C, Repici A, Rex DK. Serrated polyposis syndrome: risk stratification or reduction? Gut 2016;65:1070-1072.

43. Weisenberger DJ, Siegmund KD, Campan M, et al. CpG island methylator phenotype underlies sporadic microsatellite instability and is tightly associated with BRAF mutation in colorectal can- cer. Nat Genet 2006;38:787-793.

44. Ionov Y, Peinado MA, Malkhosyan S, Shibata D, Perucho M. Ubiquitous somatic mutations in simple repeated sequences reveal a new mechanism for colonic carcinogenesis. Nature 1993;363:558-561.

45. Fujiwara T, Stolker JM, Watanabe T, et al. Accumulated clonal genetic alterations in familial and sporadic colorectal carcinomas with widespread instability in microsatellite sequences. Am J Pathol 1998;153:1063-1078.

46. Goel A, Nagasaka T, Arnold CN, et al. The CpG island methylator phenotype and chromosomal instability are inversely correlated in sporadic colorectal cancer. Gastroenterology 2007;132:127138.

47. Sheridan TB, Fenton H, Lewin MR, et al. Sessile serrated adenomas with low- and high-grade dysplasia and early carcinomas: an immunohistochemical study of serrated lesions "caught in the act”. Am J Clin Pathol 2006;126:564-571.

48. Wong JJ, Hawkins NJ, Ward RL. Colorectal cancer: a model for epigenetic tumorigenesis. Gut 2007;56:140-148.

49. Jass JR. Classification of colorectal cancer based on correlation of clinical, morphological and molecular features. Histopathology 2007;50:113-130.

50. Kriegl L, Neumann J, Vieth M, et al. Up and downregulation of p16(Ink4a) expression in BRAF-mutated polyps/adenomas indicates a senescence barrier in the serrated route to colon cancer. Mod Pathol 2011;24:1015-1022.

51. Suzuki H, Igarashi S, Nojima M, et al. IGFBP7 is a p53-responsive gene specifically silenced in colorectal cancer with $\mathrm{CpG}$ island methylator phenotype. Carcinogenesis 2010;31:342-349.

52. Deng G, Bell I, Crawley S, et al. BRAF mutation is frequently present in sporadic colorectal cancer with methylated hMLH1, but not in hereditary nonpolyposis colorectal cancer. Clin Cancer Res 2004;10(1 Pt 1):191-195.

53. Spring KJ, Zhao ZZ, Karamatic R, et al. High prevalence of sessile serrated adenomas with BRAF mutations: a prospective study of patients undergoing colonoscopy. Gastroenterology 2006;131:1400-1407.

54. Kambara T, Simms LA, Whitehall VL, et al. BRAF mutation is associated with DNA methylation in serrated polyps and cancers of the colorectum. Gut 2004;53:1137-1144.

55. Kolch W. Meaningful relationships: the regulation of the Ras/Raf/ MEK/ERK pathway by protein interactions. Biochem J 2000;351 Pt 2:289-305.

56. Carragher LA, Snell KR, Giblett SM, et al. V600EBraf induces gastrointestinal crypt senescence and promotes tumour progression through enhanced CpG methylation of p16INK4a. EMBO Mol Med 2010;2:458-471.

57. Aust DE, Baretton GB; Members of the Working Group GI-Pathology of the German Society of Pathology. Serrated polyps of the colon and rectum (hyperplastic polyps, sessile serrated adenomas, traditional serrated adenomas, and mixed polyps)-proposal for diagnostic criteria. Virchows Arch 2010;457:291-297. 
58. Tadepalli US, Feihel D, Miller KM, et al. A morphologic analysis of sessile serrated polyps observed during routine colonoscopy (with video). Gastrointest Endosc 2011;74:1360-1368.

59. Wallace K, Grau MV, Ahnen D, et al. The association of lifestyle and dietary factors with the risk for serrated polyps of the colorectum. Cancer Epidemiol Biomarkers Prev 2009;18:2310-2317.

60. Anderson JC, Rangasamy P, Rustagi T, et al. Risk factors for sessile serrated adenomas. J Clin Gastroenterol 2011;45:694-699.

61. Kimura T, Yamamoto E, Yamano HO, et al. A novel pit pattern identifies the precursor of colorectal cancer derived from sessile serrated adenoma. Am J Gastroenterol 2012;107:460-469.

62. Hazewinkel Y, López-Cerón M, East JE, et al. Endoscopic features of sessile serrated adenomas: validation by international experts using high-resolution white-light endoscopy and narrow-band imaging. Gastrointest Endosc 2013;77:916-924.

63. Parikh ND, Chaptini L, Njei B, Laine L. Diagnosis of sessile serrated adenomas/polyps with image-enhanced endoscopy: a systematic review and meta-analysis. Endoscopy 2016;48:731-739.

64. Hewett DG, Kaltenbach T, Sano Y, et al. Validation of a simple classification system for endoscopic diagnosis of small colorectal polyps using narrow-band imaging. Gastroenterology 2012;143:599-607.

65. Kumar S, Fioritto A, Mitani A, Desai M, Gunaratnam N, Ladabaum U. Optical biopsy of sessile serrated adenomas: do these lesions resemble hyperplastic polyps under narrow-band imaging? Gastrointest Endosc 2013;78:902-909.

66. IJspeert JE, Bastiaansen BA, van Leerdam ME, et al. Development and validation of the WASP classification system for optical diagnosis of adenomas, hyperplastic polyps and sessile serrated adenomas/polyps. Gut 2016;65:963-970.

67. Nanda KS, Tutticci N, Burgess N, Sonson R, McLeod D, Bourke MJ. Caught in the act: endoscopic characterization of sessile serrated adenomas with dysplasia. Gastrointest Endosc 2014;79:864870.

68. Burgess NG, Pellise M, Nanda KS, et al. Clinical and endoscopic predictors of cytological dysplasia or cancer in a prospective multicentre study of large sessile serrated adenomas/polyps. Gut 2016;65:437-446.

69. Goldstein NS. Serrated pathway and APC (conventional)-type colorectal polyps: molecular-morphologic correlations, genetic pathways, and implications for classification. Am J Clin Pathol 2006;125:146-153.

70. Kamiński MF, Hassan C, Bisschops R, et al. Advanced imaging for detection and differentiation of colorectal neoplasia: European Society of Gastrointestinal Endoscopy (ESGE) guideline. Endoscopy 2014;46:435-449.

71. Pohl J, Schneider A, Vogell H, Mayer G, Kaiser G, Ell C. Pancolonic chromoendoscopy with indigo carmine versus standard colonoscopy for detection of neoplastic lesions: a randomised two-centre trial. Gut 2011;60:485-490.

72. Rex DK, Clodfelter R, Rahmani F, et al. Narrow-band imaging versus white light for the detection of proximal colon serrated lesions: a randomized, controlled trial. Gastrointest Endosc 2016;83:166-171.

73. Hazewinkel Y, Tytgat KM, van Leerdam ME, et al. Narrow-band imaging for the detection of polyps in patients with serrated polyposis syndrome: a multicenter, randomized, back-to-back trial. Gastrointest Endosc 2015;81:531-538.

74. Zorzi M, Senore C, Da Re F, et al. Detection rate and predictive factors of sessile serrated polyps in an organised colorectal cancer screening programme with immunochemical faecal occult blood test: the EQuIPE study (Evaluating Quality Indicators of the Performance of Endoscopy). Gut 2017;66:1233-1240.

75. Chang LC, Shun CT, Hsu WF, et al. Fecal immunochemical test detects sessile serrated adenomas and polyps with a low level of sensitivity. Clin Gastroenterol Hepatol 2017;15:872-879.e1.

76. Butterly L, Robinson CM, Anderson JC, et al. Serrated and adenomatous polyp detection increases with longer withdrawal time: results from the New Hampshire Colonoscopy Registry. Am J Gastroenterol 2014;109:417-426.

77. Hewett DG, Rex DK. Miss rate of right-sided colon examination during colonoscopy defined by retroflexion: an observational study. Gastrointest Endosc 2011;74:246-252.

78. Clark BT, Laine L. High-quality bowel preparation is required for detection of sessile serrated polyps. Clin Gastroenterol Hepatol 2016;14:1155-1162.

79. El Sayed AM, Kanafani ZA, Mourad FH, et al. A randomized single-blind trial of whole versus split-dose polyethylene glycolelectrolyte solution for colonoscopy preparation. Gastrointest Endosc 2003;58:36-40.

80. Gurudu SR, Ramirez FC, Harrison ME, Leighton JA, Crowell MD. Increased adenoma detection rate with system-wide implementation of a split-dose preparation for colonoscopy. Gastrointest Endosc 2012;76:603-608.

81. Horton N, Garber A, Hasson H, Lopez R, Burke CA. Impact of single- vs. split-dose low-volume bowel preparations on bowel movement kinetics, patient inconvenience, and polyp detection: a prospective trial. Am J Gastroenterol 2016;111:1330-1337.

82. Gralnek IM. Emerging technological advancements in colonoscopy: Third Eye ${ }^{\circledast}$ Retroscope ${ }^{\circledast}$ and Third Eye ${ }^{\circledast}$ Panoramic(TM), Fuse $^{\circledR}$ Full Spectrum Endoscopy ${ }^{\circledR}$ colonoscopy platform, ExtraWide-Angle-View colonoscope, and NaviAid(TM) G-EYE(TM) balloon colonoscope. Dig Endosc 2015;27:223-231.

83. Patil R, Ona MA, Ofori E, Reddy M. Endocuff-assisted colonoscopy-a novel accessory in improving adenoma detection rate: a review of the literature. Clin Endosc 2016;49:533-538.

84. Moriyama T, Uraoka T, Esaki M, Matsumoto T. Advanced technology for the improvement of adenoma and polyp detection during colonoscopy. Dig Endosc 2015;27 Suppl 1:40-44.

85. de Wijkerslooth TR, Stoop EM, Bossuyt PM, et al. Adenoma detection with cap-assisted colonoscopy versus regular colonoscopy: a randomised controlled trial. Gut 2012;61:1426-1434.

86. van Doorn SC, van der Vlugt M, Depla A, et al. Adenoma detection with Endocuff colonoscopy versus conventional colonosco- 
py: a multicentre randomised controlled trial. Gut 2017;66:438445.

87. Repici A, Hassan C, Vitetta E, et al. Safety of cold polypectomy for $<10 \mathrm{~mm}$ polyps at colonoscopy: a prospective multicenter study. Endoscopy 2012;44:27-31.

88. Lee CK, Shim JJ, Jang JY. Cold snare polypectomy vs. cold forceps polypectomy using double-biopsy technique for removal of diminutive colorectal polyps: a prospective randomized study. Am J Gastroenterol 2013;108:1593-1600.

89. Kim JS, Lee BI, Choi H, et al. Cold snare polypectomy versus cold forceps polypectomy for diminutive and small colorectal polyps: a randomized controlled trial. Gastrointest Endosc 2015;81:741747.

90. Raad D, Tripathi P, Cooper G, Falck-Ytter Y. Role of the cold biopsy technique in diminutive and small colonic polyp removal: a systematic review and meta-analysis. Gastrointest Endosc 2016;83:508-515.

91. Metz AJ, Moss A, McLeod D, et al. A blinded comparison of the safety and efficacy of hot biopsy forceps electrocauterization and conventional snare polypectomy for diminutive colonic polypectomy in a porcine model. Gastrointest Endosc 2013;77:484-490.

92. Burgess NG, Bahin FF, Bourke MJ. Colonic polypectomy (with videos). Gastrointest Endosc 2015;81:813-835.

93. Hewett DG. Cold snare polypectomy: optimizing technique and technology (with videos). Gastrointest Endosc 2015;82:693-696.

94. Din S, Ball AJ, Riley SA, Kitsanta P, Johal S. Cold snare polypectomy: does snare type influence outcomes? Dig Endosc 2015;27:603-608

95. Horiuchi A, Hosoi K, Kajiyama M, Tanaka N, Sano K, Graham DY. Prospective, randomized comparison of 2 methods of cold snare polypectomy for small colorectal polyps. Gastrointest Endosc 2015;82:686-692.

96. Chukmaitov A, Bradley CJ, Dahman B, Siangphoe U, BouHaidar D, Warren JL. Polypectomy techniques, endoscopist characteristics, and serious gastrointestinal adverse events. J Surg Oncol 2014;110:207-213.

97. Ko CW, Riffle S, Michaels L, et al. Serious complications within 30 days of screening and surveillance colonoscopy are uncommon. Clin Gastroenterol Hepatol 2010;8:166-173.

98. Fujiya M, Sato H, Ueno N, et al. Efficacy and adverse events of cold vs hot polypectomy: a meta-analysis. World J Gastroenterol 2016;22:5436-5444.

99. Paspatis GA, Tribonias G, Konstantinidis K, et al. A prospective randomized comparison of cold vs hot snare polypectomy in the occurrence of postpolypectomy bleeding in small colonic polyps. Colorectal Dis 2011;13:e345-e348.

100. Ichise Y, Horiuchi A, Nakayama Y, Tanaka N. Prospective randomized comparison of cold snare polypectomy and conventional polypectomy for small colorectal polyps. Digestion 2011;84:7881.

101. Tutticci N, Burgess NG, Pellise M, Mcleod D, Bourke MJ. Characterization and significance of protrusions in the mucosal defect after cold snare polypectomy. Gastrointest Endosc 2015;82:523528.

102. Moss A, Bourke MJ, Williams SJ, et al. Endoscopic mucosal resection outcomes and prediction of submucosal cancer from advanced colonic mucosal neoplasia. Gastroenterology 2011;140:1909-1918.

103. Ferrara F, Luigiano C, Ghersi S, et al. Efficacy, safety and outcomes of 'inject and cut' endoscopic mucosal resection for large sessile and flat colorectal polyps. Digestion 2010;82:213-220.

104. Rao AK, Soetikno R, Raju GS, et al. Large sessile serrated polyps can be safely and effectively removed by endoscopic mucosal resection. Clin Gastroenterol Hepatol 2016;14:568-574.

105. Rex KD, Vemulapalli KC, Rex DK. Recurrence rates after EMR of large sessile serrated polyps. Gastrointest Endosc 2015;82:538541.

106. Liang J, Kalady MF, Church J. Snaring large serrated polyps. Surg Endosc 2013;27:1622-1627.

107. Pellise M, Burgess NG, Tutticci N, et al. Endoscopic mucosal resection for large serrated lesions in comparison with adenomas: a prospective multicentre study of 2000 lesions. Gut 2017;66:644653.

108. Cha JM, Lim KS, Lee SH, et al. Clinical outcomes and risk factors of post-polypectomy coagulation syndrome: a multicenter, retrospective, case-control study. Endoscopy 2013;45:202-207.

109. Burgess NG, Metz AJ, Williams SJ, et al. Risk factors for intraprocedural and clinically significant delayed bleeding after widefield endoscopic mucosal resection of large colonic lesions. Clin Gastroenterol Hepatol 2014;12:651-661.

110. Burgess NG, Williams SJ, Hourigan LF, et al. A management algorithm based on delayed bleeding after wide-field endoscopic mucosal resection of large colonic lesions. Clin Gastroenterol Hepatol 2014;12:1525-1533.

111. Pattullo V, Bourke MJ, Tran KL, et al. The suction pseudopolyp technique: a novel method for the removal of small flat nonpolypoid lesions of the colon and rectum. Endoscopy 2009;41:10321037.

112. Din S, Ball AJ, Riley SA, Kitsanta P, Johal S. A randomized comparison of cold snare polypectomy versus a suction pseudopolyp technique. Endoscopy 2015;47:1005-1010.

113. Choksi N, Elmunzer BJ, Stidham RW, Shuster D, Piraka C. Cold snare piecemeal resection of colonic and duodenal polyps $\geq 1 \mathrm{~cm}$. Endosc Int Open 2015;3:E508-E513.

114. Muniraj T, Sahakian A, Ciarleglio MM, Deng Y, Aslanian HR. Cold snare polypectomy for large sessile colonic polyps: a singlecenter experience. Gastroenterol Res Pract 2015;2015:175959.

115. Klein A, Bourke MJ. Advanced polypectomy and resection techniques. Gastrointest Endosc Clin N Am 2015;25:303-333.

116. Holt BA, Bourke MJ. Wide field endoscopic resection for advanced colonic mucosal neoplasia: current status and future directions. Clin Gastroenterol Hepatol 2012;10:969-979.

117. Buchner AM, Guarner-Argente C, Ginsberg GG. Outcomes of EMR of defiant colorectal lesions directed to an endoscopy refer- 
ral center. Gastrointest Endosc 2012;76:255-263.

118. Swan MP, Bourke MJ, Alexander S, Moss A, Williams SJ. Large refractory colonic polyps: is it time to change our practice? A prospective study of the clinical and economic impact of a tertiary referral colonic mucosal resection and polypectomy service (with videos). Gastrointest Endosc 2009;70:1128-1136.

119. Hassan C, Quintero E, Dumonceau JM, et al. Post-polypectomy colonoscopy surveillance: European Society of Gastrointestinal Endoscopy (ESGE) guideline. Endoscopy 2013;45:842-851.

120. Cancer Council Australia Colonoscopy Surveillance Working Party. Clinical practice guidelines for surveillance colonoscopyin adenoma follow-up: following curative resection of colorectal cancer; and for cancer surveillance in inflammatory bowel disease. Sydney: Cancer Council Australia, 2011. 